\title{
Seasonal prevalence and histopathology of Beauveria bassiana infecting larvae of the leopard moth, Zeuzera pyrina L. (Lepidoptera: Cossidae)
}

\author{
Reda Ibrahim ${ }^{1,2^{*}}$ D, Saeed Alahmadi ${ }^{1}$, Yaser S. Binnaser ${ }^{1}$ and Dalia Shawer ${ }^{2}$
}

\begin{abstract}
The natural epizootic potential of the fungus, Beauveria bassiana, against larvae of the leopard moth, Zeuzera pyrina L. (Lepidoptera: Cossidae) was investigated under natural conditions in two different locations for two seasons (2015-2016 and 2016-2017) in Rasheed, Behiara Governorate, Egypt. In an orchard, located in the old cultivated land, Beauveria infected 1.9-5.6\% of larvae of Z. pyrina in autumn (September to November), increased to 3.4-7.2\% in winter (December to February). The infection did not exceed 3.1\% in spring (March to May), and no infection was recorded in summer (June to August). While in an olive farm, located in a newly reclaimed land, in both seasons of survey, no infections were recorded from May to September, while in winter, the epizootics ranged from 1.4-3.1\%, from 0.4 to $1.3 \%$ in spring, and from 0.3 to $2.1 \%$ in autumn. Histopathological analysis revealed that Beauveria most commonly penetrated larvae directly through the intersegmental integument and the first symptoms were observed 3 to 4 days later. Hyphae radiated inward from the point of ingress and the fungus developed sparsely within the body cavity prior to the death of the larva. Hyphal bodies were concentrated around the point of ingress, but some were found at distance from this site. Only in the vicinity of penetration, the hypodermis showed signs of histolysis. The saprophytic phase developed rapidly and the fungus invaded all internal organs. The conidiophores seemed to rupture the cuticle by mechanical pressure and emerged all over the host cadaver, with sporulation occurring $48 \mathrm{~h}$ later. Pathological changes in the hemolymph appeared to be the primary cause of larval mortality.
\end{abstract}

Keywords: Natural epizootics, Mode of infection, Beauveria bassiana, Zeuzera pyrina, Histopathology

\section{Background}

Orchards harbor one of the most complex agroecosystems as a result of their perennial nature. Pear, apple, peach, and olive orchards are attacked by several serious insect pests. Among these insects, several species of genus Zeuzera (Lepidoptera: Cossidae) are infesting those orchards in many Arabian countries, especially in North Africa (Hegazi et al. 2014). In the last few decades, the leopard moth, Zeuzera pyrina L., has emerged as a major polyphagous pest of a wide variety of pome and stone fruits and bushes such as currant,

\footnotetext{
*Correspondence: reda_ibrahim18@yahoo.com

'Biology Department, Faculty of Science, Taibah University, Medina, Saudi

Arabia

2Department of Entomology, Kafrelsheikh University, Kafrelsheikh, Egypt
}

comprising over 150 plant species (El-Husseini et al. 2018). In Egypt, damage caused by Zeuzera larvae has led to uprooting of infested pome orchards by growers because its monitoring and control is extremely difficult.

Several trials have been undertaken to control the leopard moth borer, e.g., by using pheromones, mass trapping, and mating disruption (Avilla and Bosch 2001 and Abed El-Hadi et al. 2005) or the entomopathogenic fungi and nematodes (Abdel-Kawy et al. 1992 and Patanita 2006). Presently, the management of $Z$. pyrina at orchards facilities is either non-existent (by smallholder farmers) or depends on the application of organic and/or synthetic pesticides in large areas (Chouinard et al. 2016). However, the application of these compounds has become increasingly problematic 
due to concerns about hazards to human health, environment, and pest resistance (Atreya et al. 2012).

Due to the cryptic habitat of the larvae inside the branches and the long ovipositional period, chemical control applications of this pest are less successful (Shamseldean et al. 2009). This encouraged the search for effective and safe alternative control agents against Zeuzera larvae. In this context, recent studies reported that certain cossid larvae have been already listed as susceptible to attack by certain entomopathogenic nematodes and fungi (Ashtari et al. 2011).

It could be assumed that native isolates of entomopathogenic fungi (EPF) may provide better control of this cossid than other introduced ones, because it is well adapted to local climatic conditions (Wraight et al. 2018). Beauveria bassiana proved to be a virulent bioagent against several insect pests by producing a variety of extracellular hydrolytic and proteolytic enzymes that degrading the integument of its host (Dhawan and Joshi 2017). Many experiments have been carried out to determine the feasibility of using these fungi for the biological control for such borers (Ashtari et al. 2011 and Wraight et al. 2018). Several native isolates were characterized, but information about their biocontrol potential in the field is rare. Therefore, the natural role of EPF as limiting agents for Zeuzera larvae should be reevaluated.

Thus, the present study was aimed to determine the seasonal prevalence of B. bassiana in $Z$. pyrina larvae under natural conditions and to investigate the histopathology of B. bassiana in the larvae of Zeuzera prior and after their death.

\section{Materials and methods}

\section{Seasonal prevalence of $B$. bassiana in Z. pyrina larvae}

Close observations and preliminary differential diagnosis have approved the presence of mycosed $Z$. pyrina larvae. Sampling was carried out in two farms, both are different from each other; geographically, environmentally, dominant weather conditions, and type of soil. The first was an old mixed orchard (apple and pear trees) located in Rasheed,

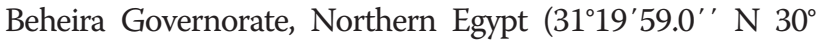
$27^{\prime} 17.2^{\prime \prime}$ E), and the second was a newly reclaimed land, cultivated with different olive varieties (10 years old), located in an arid area, $80 \mathrm{~km}$ north of Cairo (30 $14^{\prime} 15.4^{\prime \prime}$ ' N 30 $41^{\prime}$ $54.2^{\prime \prime}$ E). Biweekly sampling of infested branches with $Z$. pyrina larvae, starting from March 2015 to February 2017, were collected according to Hegazi et al. (2010, 2014). Each sample consisted of 20 infested branches, of about 50-80 $\mathrm{cm}$ long and $2-5 \mathrm{~cm}$ diameter. In the laboratory, branches were carefully dissected and both alive and dead larvae were counted. Zeuzera larvae were carefully examined for the presence of symptoms and signs of infections. Alive ones were reared until death or further development inside their tunnels. Larvae were daily examined, and dead ones were segregated and subjected to histopathological investigations and mycosis test as described by Kocaçevik et al. (2016). Cadavers of larvae showed external growth of the fungus and were considered killed by the fungus. Incidence of $B$. bassiana was calculated as percentage of larvae killed by the fungus. Both discoloration and physical condition of the cadavers were characterized. Mortality percentage of Zeuzera larvae was assessed after mycosis test of each sample.

\section{Mycosis test}

Dead larvae were collected in sterilized Petri dishes and subjected to diagnostic examination to identify the fungus. Samples of conidia from Zeuzera larval cadavers, with visible fungal sporulation, were streaked on potato dextrose agar (PDA) and incubated at $28 \pm 1{ }^{\circ} \mathrm{C}$. Afterwards, B. bassiana were isolated as pure culture after growth and sporulation on PDA media. Whereas larval cadavers without visible fungal sporulation were plated individually on water agar with chloramphenicol and incubated as described by Wraight et al. (2018). On the other hand, rigid cadavers, which collected either directly from the field or resulted from the dissected branches were treated by $0.5 \%$ sodium hypochlorite for $10 \mathrm{~s}$, rinsed in distilled water for $20 \mathrm{~s}$, and then arranged on filter papers inside Petri dishes. Petri dishes containing larval cadavers were kept at $25 \pm 1$ ${ }^{\circ} \mathrm{C}$ and $>90 \%$ R.H. The filter paper was moistened with sterile distilled water daily to ensure humidity maintenance. Based on conidiophore and conidia morphology, the isolated fungus was identified as B. bassiana. Larvae were daily examined for external sporulation of fungus that death was most likely due to mycosis caused by the fungal isolate (Ansari and Butt 2012). The identification of developing fungal colonies and confirmation of its pathogenicity were carried out according to Destéfano et al. (2004) and Reay et al. (2008).

\section{Histopathology}

In order to record both signs and symptoms of Beauveria infection, naturally infected larvae of $Z$. pyrina were further reared until death on fragmented branches of pear and apple in a sterilized bucket. Moreover, for comparison to naturally infected ones, healthy $Z$. pyrina larvae were sprayed with conidia of Beauveria and daily investigated. At the same time, some specimens of naturally infected larvae were dissected and smears of hemolymph and fat bodies were examined, using a phase-contrast microscope (Wang et al. 2004). Meanwhile, to ensure and accurately follow up progress and development of infection, diseased and dead larvae were subjected to a histopathological procedure. Specimens of mycosed larvae were fixed in Bouin's solution, dehydrated in ethanol, and then treated with methyl-benzoate and benzol. Samples were sectioned, using procedures of Duan et al. (2017). 


\section{Statistical analysis}

Data of mycosed Zeuzera larvae were statistically analyzed by one-way analysis of variance. The means and standard deviations were separated by Tukey's honest significant difference test $(P<0.05)$, using the Biostat 2008 statistical analysis program (Copyright $\odot$ 2001-2009 Analystsoft).

\section{Results and discussion}

\section{The pathogen and pathogenicity}

Field observations conducted in pome orchards indicated the presence of infected and dead larvae of the leopard moth, Z. pyrina, which exhibited abnormalities in color, size, and shape. Dead larvae were rigidly mummified. Some of the dead larvae were found sticking at/near the openings of galleries on branches and covered with white thin mycelial growth of Beauveria. Larvae of $Z$. pyrina, collected from pome orchards, were found to be infected with the EPF, $B$. bassiana, which is commonly referred to as the white muscardine fungus. Alive infected larvae were feeble with large irregular dark brown areas on the cuticle. In Indonesia, Utomo et al. (1988) isolated a strain of Beauveria sp. from the dead larvae of the cocoa red borer, Zeuzera coffeae. Zhu and Ma (1985) isolated B. bassiana from dead larvae of Carpocapsa pomonella collected from apple orchards. The isolated strain was highly pathogenic to different lepidopterous larvae including Z. pyrina. In a related study, Sewify and Sharaf El-Din (1993) reported that larvae of Z. pyrina were susceptible to the infection with Metarhizium anisopliae under laboratory conditions.

\section{Prevalence of Beauveria in larvae of Zeuzera}

Although, the prevalence of Beauveria in larvae of Zeuzera was higher in the second year than in the first one, there was insignificant difference between the 2 years of survey, except mortalities of November and January in the mixed orchard $(P \leq 0.05)$. Obtained data of the present study revealed that in two successive years, there were significant differences in the prevalence of Beauveria in larval population of Zeuzera $(P \leq 0.05)$ between the two investigated farms (Fig. 1). Generally, it seems that larval mycoses are density-dependent. For example, first larval infection was recorded in the second week of September, but the fungus prevalence was low (1.9\%) and increased gradually to reach the highest mortality (7.2\%) in December (Fig. 2). In both years of study, the peak of fungus infection was recorded in December and January reaching 7.2 and $5.9 \%$, respectively. It was coincident with the peak of population density of larvae. Although, the olive farm was ecologically managed, in both years of survey, no infections were recorded from May to September. In winter, the epizootics ranged from 1.4 to $3.1 \%$, whereas it ranged between 0.4 and $1.3 \%$ in spring, and 0.3 and $2.1 \%$ in autumn. However, insignificant differences were recorded in the prevalence of Beauveria in larval population of Zeuzera $(P \leq 0.05)$ between the 2 years of survey in olive farm. Olive trees were approximately 10 years old. The low mortality percentage among Zeuzera larvae could be attributed to low load of Beauveria inoculum in the newly reclaimed desert lands. Epizootics recorded in this farm was comparable to that recorded (1.6\%) by Hegazi et al. (2014).

Likely, the behavior of larvae, e.g., overcrowding in galleries, abundance of young susceptible larvae and the dominant environmental conditions, particularly during winter allowed a successful infection and easily spread of Beauveria within larval population. In this context, the field dissection of infested olive branches showed that a large number of leopard larvae of

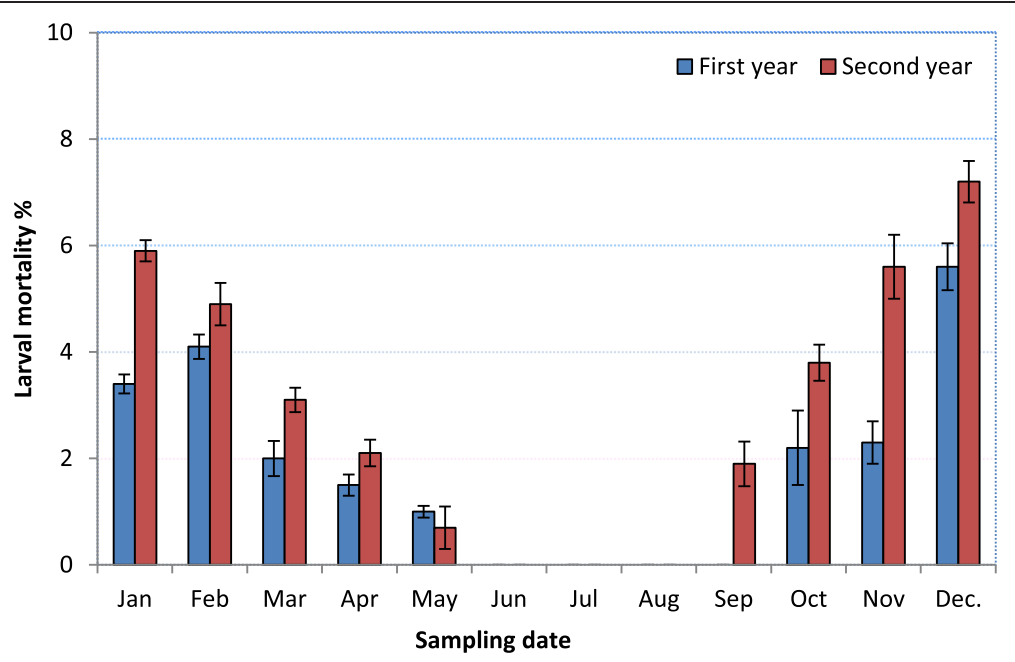

Fig. 1 Seasonal prevalence of Beauveria bassiana on Zeuzera pyrina larvae in pome orchards, throughout two seasons (2015-2016 \& 2016-2017) ( \pm SEM) 
different instars remained in a dormant stage for overwintering (Hegazi et al. 2014). The same authors have investigated 245 Zeuzera larvae in September and recorded that $1.6 \%$ of them infected with $B$. bassiana. During the first year, no larval mortalities were recorded in the period from May to September, while $1.9 \%$ was recorded during September of the second year. This could be attributed to behavior of larvae and the dominant environmental conditions in summer months (Sarto 2001). Ecological studies revealed that most of Zeuzera larvae were much smaller, continuing to feed throughout the season and become fully grown only in the late summer (Ismail et al. 1992; Hegazi et al. 2009 and Merghem and Ahmed 2017). In Spring, the prevalence of Beauveria in larvae of Zeuzera was significantly less than in winter which may be due to the larvae that started feeding and boring into branches, and majority of larvae became full-grown and ready for pupation, thus may be more resistant to infection. The low activity of the naturally occurring Beauveria in spring and summer may be due to negative impacts of low host density and/or reduced fungal inoculum load in sprayed or sanitized pome orchards (Hegazi et al. 2014). The same trend was also reported by (Wraight et al. 2018).

The inoculums source may be the larval cadavers in galleries or fungus spores occurring in orchard's soil. However, regarding the fungus transmission, likely by direct contact between active larvae and cadavers embedded in galleries. Sun et al. (2008) surveyed a total of 20 species of insect-associated fungi in orchard soils. The survey included insect-pathogenic fungi and opportunistic insect pathogens. They recorded three insect-pathogenic species, B. bassiana, Metarhizium anisopliae, and Paecilomyces fumosoroseus.

\section{Histopathological analysis}

The insect cuticle is a highly heterogeneous structure that can vary greatly in composition even during the various life-stages of a particular insect. The EPF induce infection via penetration essentially anywhere on the host cuticle, although preferential sites have been noted on various insects (Ashtari et al. 2011 and Sahayaraj et al. 2013). Histopathological studies indicated that the fungus conidia germinated on the cuticle surface with a thin germ hypha which penetrated into the cuticle 2 days after contamination (Fig. 3a). Ortiz-Urquiza and Keyhani (2013) reported that infection begins with attachment of single-celled dispersive forms of the fungus, e.g., conidia or blastospores, to the insect cuticle. However, the penetration was observed mainly on the intersegmental areas and at sites where masses of germ hyphae were detected, probably due to the absence of cuticulin in this area of the integument (Fig. 3b, c). The epicuticle layer provides a hydrophobic barrier rich in lipids and is followed by the procuticle that contains chitin and sclerotized protein (Hajek and Leger 1994 and Ortiz-Urquiza and Keyhani 2013). Elsayed et al. (1989) detected high levels of both endo- and exochitinase activity in penetration sites of Nomuraea rileyi into larva of cabbage looper, Trichoplusia ni. On the penetration sites, the outer part of the cuticle changed into a dark brown color (dark spots), while the endocuticle appeared degraded near the penetrant hyphae which indicates the formation of appressorium (Fig. 4c, d). In contrast, Schneider et al. (2013) reported that the adhesion stage and formation of the appressorium noticed 18 $\mathrm{h}$ after the infection, occasioning black spots, and depressions in the cuticle of young and old infected pupae of Diatraea saccharalis. Similarly, Vega et al.

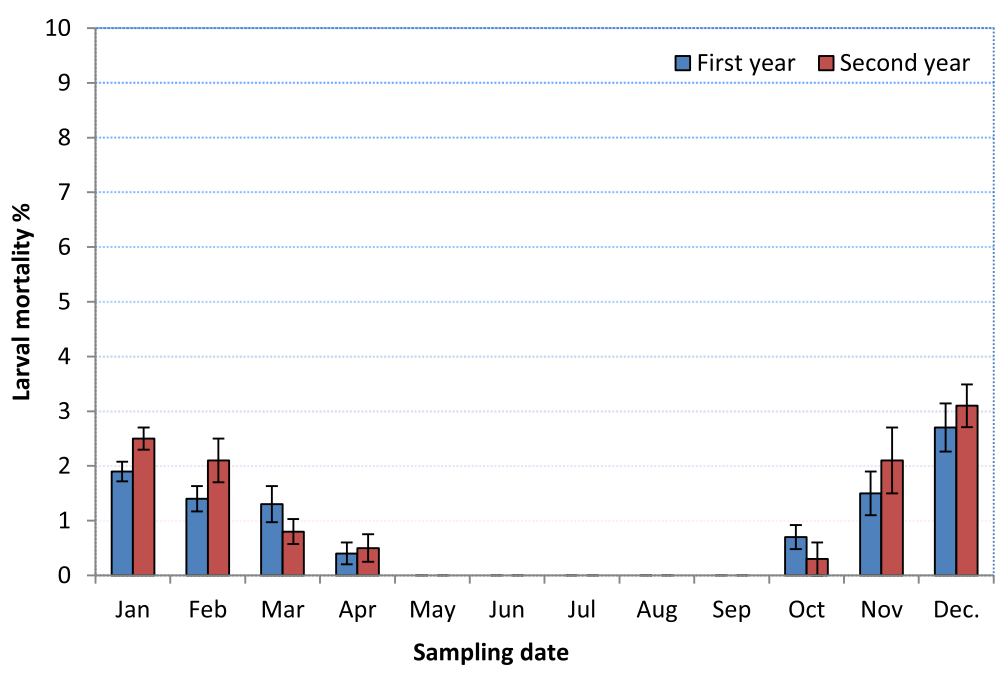

Fig. 2 Seasonal prevalence of Beauveria bassiana in Zeuzera pyrina larvae in olives farm, throughout two seasons (2015-2016 \& 2016-2017) ( \pm SEM) 
(2015) mentioned that B. bassiana was accomplished penetration into the coffee berry borer, Hypothenemus hampei, within a few hours, but required several days to infect and kill it. Six days after infection, the saprophytic phase of Beauveria was recorded. The hyphal bodies and blastospores of the fungus were observed in large numbers in the body cavity. Prior to death, the hyphae were abundant in most of the body tissues. After death, the larvae cadavers were soft and pliable but became rigid and mummified within $24 \mathrm{~h}$ at $25{ }^{\circ} \mathrm{C}$. When rigid cadavers were maintained at $25{ }^{\circ} \mathrm{C}$ and $100 \%$ R.H., they were completely covered by the fungus mycelia within 4-7 days (Fig. 4c). The development of B. bassiana into the larvae of $\mathrm{Z}$. pyrina was similar to that recorded for the fungus in coffee berry borer $H$. hampei (Wraight et al. 2018) and the red palm weevil, Rhynchophorus ferrugineus (Dembilio et al. 2010). Müller-Kögler (1965) divided the life cycle of EPF into two phases; the parasitic phase in which the fungus infects and kills its host; and the saprophytic phase in which the fungus grows on the surface of the cadavers, producing conidiophores and conidia (Fig. 4d). The above two phases are distinct in the present study for Zeuzera larvae. Smears of hemolymph and fat bodies of infected larvae indicated the presence of short branched hyphae with dense cytoplasm and blastospores. When rigid cadavers were subjected to humid conditions (about 100\% R.H.), the fungus grew on the surface of the cuticle with a white, fine, and thin mycelial growth. Within 2-3 days, the hyphae began to form spores. Most of the infected larvae were in their third instar. The occurrence of hyphal bodies of different sizes and dense cytoplasm in the body cavity penetrating all body tissues. Figure $3 d$ illustrates the formation of the conidiophores bearing conidia spores and indicating the extrusion. Sewify and Sharaf El-Din (1993) found that the blastospores of M. anisopliae were noticed in hemolymph of infected larvae $24 \mathrm{~h}$ after infection and developed to hyphal bodies $36 \mathrm{~h}$ after infection.

\section{Conclusion}

There were no larval mortalities recorded in summer for both seasons of survey at both sites. The natural epizootics of Beauveria had a temporal potential to suppress the leopard moth, at least under certain conditions. Histopathological analysis showed an evidence of chitinolysis. The fungus commonly penetrated through the intersegmental areas of the integument. Prior to the death of the host, the fungus was found to develop sparsely within the body cavity. Some hyphae radiated inward from the point of ingress. It could be concluded that it cannot be relied alone upon naturally occurring Beauveria for controlling the leopard moth borer in pome orchards, unless within an IPM program. Another limiting factor which impacts the natural epizootics is the host-density dependence of Beauveria
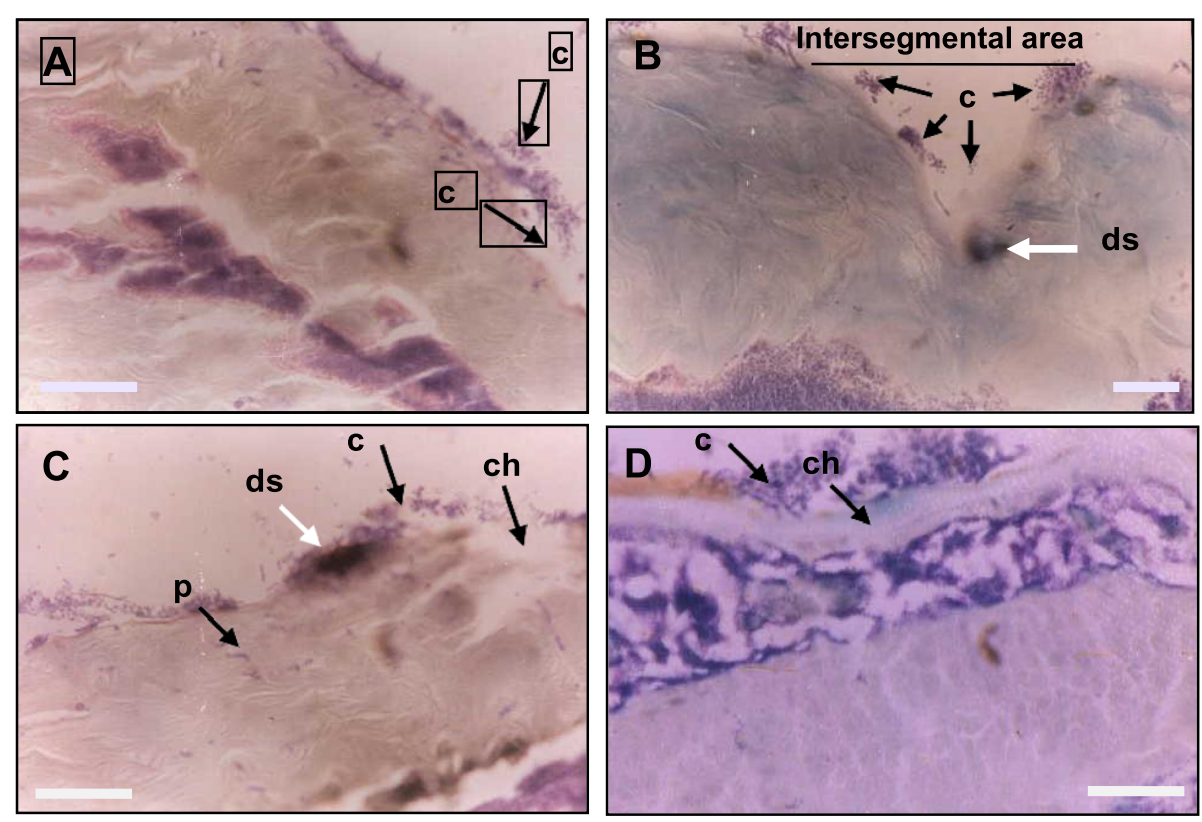

Fig. 3 Cross sections of Zeuzera pyrina larva infected with Beauveria bassiana showing the parasitic phase of the fungus. a Conidial aggregations on the epicuticle and its chitinolytic activity. $\mathbf{b}$ Aggregates of conidia mainly at the intersegmental area with dark spots. $\mathbf{c}$ Progression in penetration process showing penetrant hypha, dark spots and chitinolytic activity. $\mathbf{d}$ Progression in chitinolysis process and conidial aggregations. c, conidia; ch, chitionlytic activity; p, penetrant hypha; ds, dark spots $(X=450)$ 

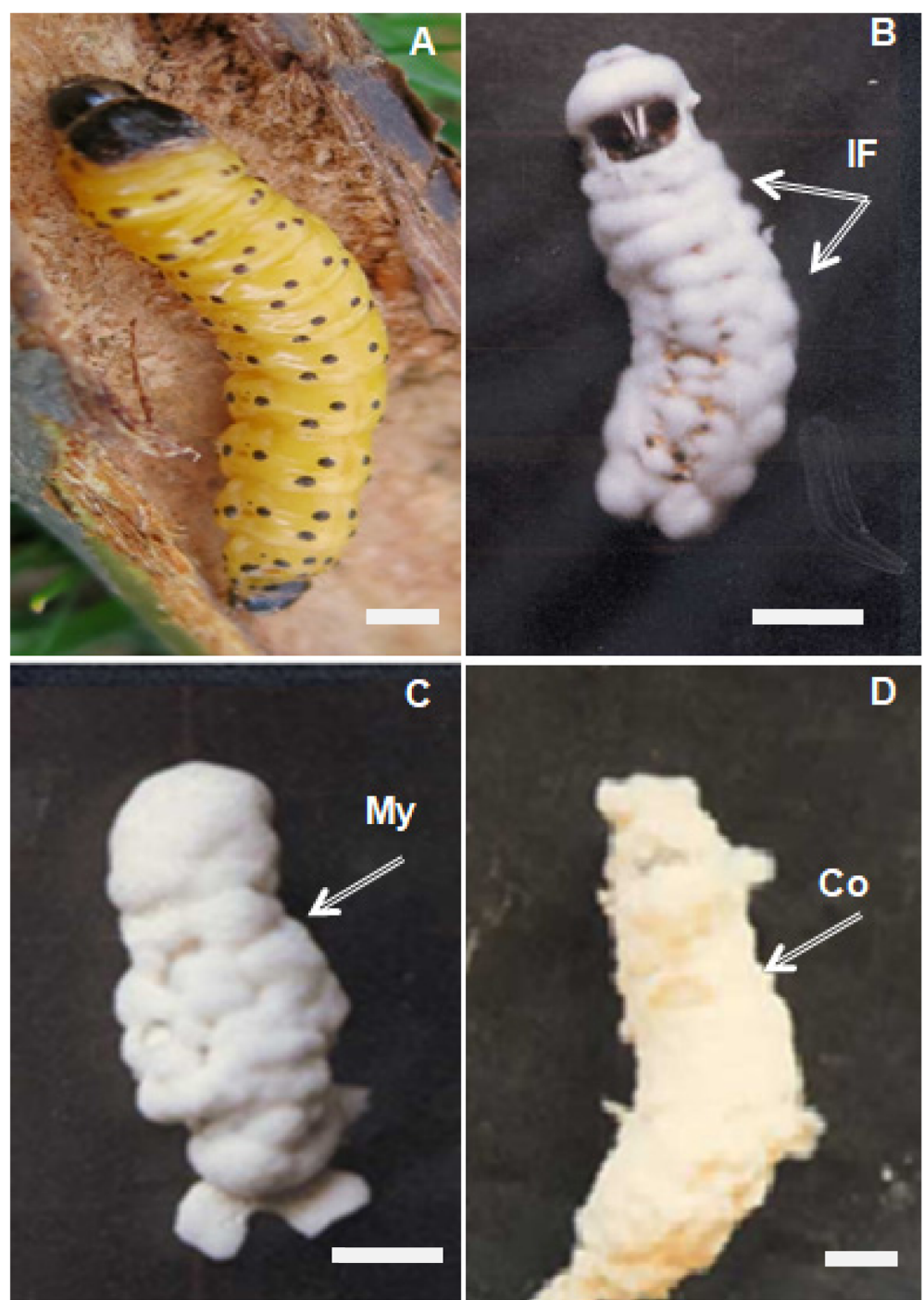

Fig. 4 External symptoms of Zeuzera pyrina Larva infected with Beauveria bassiana. a A healthy larva (bright yellow with many small black spots on each segment). $\mathbf{b}$ At 7 days after incubation, larva was partially covered with mycelia, Beauveria egress first and more thickly via

intersegmental folds (IF) of the cuticle. c At 13 days after inoculation, the larval cadaver was fully covered by bright white mycelia (My). d At 18 days after inoculation, the conidia formatted and the insect cadaver color turned into white-yellowish. $(X=40)$

transmission. Moreover, while the pathogenic fungus penetrates the larvae within hours, it requires several days to infect and kill Zeuzera larvae. Accordingly, it is unexpected that natural epizootics of the entomopathogenic fungus $B$. bassaian can provide protection either to some orchards or olive from significant damage or hold the leopard moth borer, Z. pyrina, populations below economic threshold, even under highly favorable environmental conditions.

\section{Acknowledgements}

We are grateful to Prof. Salama Ouf for critically reviewing the manuscript. We also thank everybody who provided help during this study.

\section{Authors' contributions}

All authors achieved experiments, wrote, read, and approved the final manuscript.

\section{Funding}

Not applicable

\section{Availability of data and materials}

Not applicable

\section{Ethics approval and consent to participate}

Not applicable, because our manuscript report neither studies involving human participants nor human data or human tissue.

\section{Consent for publication}

Not applicable

\section{Competing interests}

The authors declare that they have no competing interests. 
Received: 29 April 2019 Accepted: 20 August 2019

Published online: 07 October 2019

\section{References}

Abdel-Kawy A, El-Bishry H, El-Kifl T (1992) Controlling the leopard moth borer, Zeuzera pyrina by three entomopathogenic nematodes in the field. Bull Faculty Agric Cairo Univ 43(2):769-780

Abed El-Hadi A, Birger R, Hanoch E, Vardi Y, Sarid D, Zemer B (2005) Control of Zeuzera pyrina in olives by using pheromone male confusing. Alon Ha'notea 59:383-385

Ansari M, Butt T (2012) Susceptibility of different developmental stages of large pine weevil Hylobius abietis (Coleoptera: Curculionidae) to entomopathogenic fungi and effect of fungal infection to adult weevils by formulation and application methods. J Invertebr Pathol 111:33-40

Ashtari M, Karimi J, Rezapanah M, Hassani-kakhki M (2011) Biocontrol of leopard moth, Zeuzera pyrina L. (Lep.: Cossidae) using entomopathogenic nematodes in Iran. IOBC/wprs Bulletin 66:333-335

Atreya K, Johnse F, Sitaula B (2012) Health and environmental costs of pesticide use in vegetable farming in Nepal. Environ Dev Sustain 14:477-493

Avilla J, Bosch D (2001) Mass trapping and mating disruption for the control of leopard moth and apple clearwing moth. IOBC/WPRS Bull. 24:167-172

Chouinard G, Firlej A, Cormier D (2016) Going beyond sprays and killing agents: Exclusion, sterilization and disruption for insect pest control in pome and stone fruit orchards. Scientia Horticulturae 208:13-27

Dembilio O, Quesada-Moraga E, Santiago-Alvarez C, Jacas J (2010) Potential of an indigenous strain of the entomopathogenic fungus Beauveria bassiana as a biological control agent against the red palm weevil, Rhynchophorus ferrugineus. J Invertebr Pathol 104:214-221

Destéfano R, Destéfano S, Messias C (2004) Detection of Metarhizium anisopliae var. anisopiae within infected sugarcane borer Diatraea saccharalis (Lepidoptera, Pyralidae) using specific primers. Genet Mol Biol 27(2):245-252

Dhawan M, Joshi N (2017) Enzymatic comparison and mortality of Beauveria bassiana against cabbage caterpillar Pieris brassicae LINN. Braz J Microbiol 48: 522-529

Duan Y, Wu H, Ma Z, Yang L, Ma D (2017) Scanning electron microscopy and histopathological observations of Beauveria bassiana infection of Colorado potato beetle larvae. Microbial Pathogenesis 111:435-439

El-Husseini M, El-Heneidy A, Awadallah K (2018) Natural enemies associated with some economic pests in Egyptian agro-ecosystems. Egyptian J Biol Pest Control 28:78

Elsayed G, Coudron T, Ignoffo C (1989) Chitinolytic Activity and Virulence Associated with Native and Mutant Isolates of an Entomopathogenic Fungus, Nomuraea rileyi. J Invertebr Pathol 54:394-403

Hajek A, Leger R (1994) Interactions Between Fungal Pathogens and Insect Hosts. Ann Rev Entomol 39:293-322

Hegazi E, Khafagi W, Konstantopoulou M (2009) Efficient mass-trapping method as an alternative tactic for suppressing populations of leopard moth (Lepidoptera: Cossidae). Ann Entomol Soc Am 102:809-818

Hegazi E, Khafagi W, Konstantopoulou M, Schlyter F, Raptopoulos D, Shweil S, Abd El-Rahman S, Atwa A, Ali S, Tawfik H (2010) Suppression of leopard moth (Lepidoptera: Cossidae) populations in olive trees in Egypt through mating disruption. J Econ Entomol 103(5):1621-1627. https://doi.org/10.1603/EC09435

Hegazi E, Schlyter F, Khafagi W, Atwa A, Agamy E, Konstantopoulou M (2014) Population dynamics and economic losses caused by Zeuzera pyrina, a cryptic wood-borer moth, in an olive orchard in Egypt. Agric Forest Entomol. https://doi.org/10.1111/afe.12075

Ismail I, Abouzeid N, Abdallah F (1992) Population dynamics of the leopard moth, Zeuzera pyrina L., and its control on olive trees in Egypt. Z Pflanzenkr Pflanzenschutz 99:519-524

Kocaçevik S, Sevim A, Eroğlu M, Demirbağ Z, Demir I (2016) Virulence and horizontal transmission of Beauveria pseudobassiana S.A. Rehner \& Humber in Ips sexdentatus and Ips typographus (Coleoptera: Curculionidae). Turk J Agric For 40:241-248

Merghem A, Ahmed A (2017) Leopard Moth Borer, Zeuzera pyrina L. (Lepidoptera: Cossidae) threat to olive trees, Olea europaea L. (Lamiales: Oleaceae) in Fayoum Governorate and its suppressing trials using IPM tactics. Egypt Acad J Biolog Sci 9(3):99-107

Müller-Kögler E (1965) Pilzkrankeiten bei Insekten. Verlag Paul Parey, Berlin und Hamburg, p 444
Ortiz-Urquiza A, Keyhani N (2013) Action on the surface: entomopathogenic fungi versus the insect cuticle. Insects 4:357-374. https://doi.org/10.3390/ insects4030357

Patanita MI (2006) Control integrado del taladro Amarillo (Zeuzera pyrina L.) en nogales de Alentego (Portugal). Ph.D. dissertation. Universidad de Córdoba Spain. Google Scholar

Reay S, Brownbridge M, Cummings N, Nelson T, Souffre B, Lignon C, Glare T (2008) Isolation and characterization of Beauveria spp. associated with exotic bark beetles in New Zealand Pinus radiata plantation forests. Biological Control 46(3):484-494

Sahayaraj K, Borgio J, Lucini L (2013) Route of infection and hematological effect of Metarhizium anisopliae (Metsch.) Sorokin on Dysdercus cingulatus (Fab.) adult. J Basic Microbiol 53:1-12

Sarto V (2001) Control of leopard moth, Zeuzera pyrina L., in apple orchards in NE Spain: mating disruption technique. IOBC/WPRS Bull. 24:173-178 Google Scholar

Schneider L, Silva C, Pamphile C, Conte H (2013) Infection, colonization and extrusion of Metarhizium anisopliae (Metsch) Sorokin (Deuteromycotina: Hyphomycetes) in pupae of Diatraea saccharalis F.(Lepidoptera: Crambidae). J Entomol Nematol 5(1):1-9

Sewify GH, Sharaf El-Din A (1993) Susceptibility of the larvae of leopard moth, Zeuzera pyrina L. To infection with the Entomopathogenic fungus, Metarhizium anisopliae (Metsch.), vol 71. Bull Ent Soc Egypt, pp 185-193

Shamseldean M, Hasanain S, Rezk M (2009) Virulence of entomopathogenic nematodes against lepidopterous pests of horticultural crops in Egypt. Proceedings of the 4th conference on recent technologies in Agriculture "Challenges of Agriculture Modernization" 1:74-84

Sun D, Chen Y, Liu X (2008) Insect associated fungi in soils of field crops and orchards. Crop Prot 27:1421-1426

Utomo C, Pardede D, Salam A (1988) Beauveria sp. parasite of larvae of cocoa red borer, Zeuzera coffeae Nietn. Bull Perkebunan 19(3):137-142

Vega F, Infante F, Johnson A (2015) The genus Hypothenemus, with emphasis on H. hampei, the coffee berry borer. In: Vega F, Hofstetter R (eds) Bark Beetles, Biology and Ecology of Native and Invasive Species, vol Chapter 11, 1st edn. Elsevier, London, pp 427-494

Wang Y, Lei Z, Zhang Q, Wen J, Huang H (2004) The symptom and histopathological changes of Plutella xylostella infected by Metarhizium anisopliae. Chin J Biol Contr 20:156-160

Wraight S, Galaini-Wraight S, Howes R, Castrillo L, Carruthers R, Smith R, Matsumoto T, Keith $L$ (2018) Prevalence of naturally-occurring strains of Beauveria bassiana in populations of coffee berry borer Hypothenemus hampei on Hawai'i Island, with observations on coffee plant $-H$. hampei-B. bassiana interactions. J Invertebr Pathol 156:54-72

Zhu GJ, Ma TC (1985) Beauveria sp. isolated from the dead Larvae of Carpocapsa pomonella (Cydia pomonella). Chinese J Biol Control 1(4):44

\section{Publisher's Note}

Springer Nature remains neutral with regard to jurisdictional claims in published maps and institutional affiliations.

\section{Submit your manuscript to a SpringerOpen ${ }^{\circ}$ journal and benefit from:}

- Convenient online submission

- Rigorous peer review

- Open access: articles freely available online

- High visibility within the field

- Retaining the copyright to your article

Submit your next manuscript at $>$ springeropen.com 